\title{
Analisis Kualitas Pelayanan di Puskesmas X Menggunakan Metode Servqual dan Saran Perbaikannya
}

\author{
I Gede Asta Wido Herawan ${ }^{1}$, Julianus Hutabarat ${ }^{2}$, Dayal Gustopo ${ }^{3}$ \\ ${ }^{1,2}$ Program Studi Teknik Industri, Program Pascasarjana, Institut Teknologi Nasional Malang \\ ${ }^{33}$ Program Studi Teknik Industri S-1Institut Teknologi Nasional Malang \\ ${ }^{1)}$ E-mail: igedeasta@gmail.com
}

\begin{abstract}
Abstrak
Puskesmas $\mathrm{X}$ merupakan puskesmas yang cukup mudah untuk dijangkau masyarakat.Pelayanan kesehatan yang dilakukan oleh Puskesmas X kepada pasien belum maksimal karena masih banyak dijumpai kelemahan sehingga belum memenuhi kualitas sesuai yang diharapkan oleh masyarakat. Hal ini mengakibatkan terjadi kesenjangan antara persepsi dan ekspetasi pasien terhadap pelayanan Puskesmas X.Tujuan penelitian ini adalah mengetahui persepsi dan ekspetasi pasien terhadap kualitas pelayanan dan mengetahui dimensi Servqual yang paling berpengaruh terhadap kualitas pelayanan Puskesmas X. Metode yang digunakan adalah deskriptif kuantitatif dengananalisis mean gapuntuk mengetahuikualitas pelayanan dan analisis regresi untuk mencari dimensi Servqual yang paling berpengaruh terhadap kualitas pelayanan Puskesmas X.Hasil perhitungan mean gapdidapatkan seluruh nilainya negatif, hal ini menunjukkan adanya kesenjangan pada seluruh dimensi Servqual yang digunakan. Hasil regresi menunjukkan dimensiyang paling berpengaruh terhadap kualitas pelayanan Puskesmas $\mathrm{X}$ adalah assurance $(\mathrm{p}=0,000)$, kemudian responsiveness $(\mathrm{p}=0,000)$, tangible $(\mathrm{p}=0,001)$, empathy $(\mathrm{p}=0,002)$ dan reliability $(\mathrm{p}=0,014)$. Maka dapat disimpulkan terjadi kesenjangan antarapersepsi dan ekspetasi pasien terhadap kualitas pelayananPuskesmas X. Sedangkan dimensi yang paling berpengaruh terhadap kualitas pelayanan adalahassurance.
\end{abstract}

Kata Kunci: Persepsi, Ekspetasi, Puskesmas X, Servqual

\section{Pendahuluan}

Puskesmas $\mathrm{X}$ mempunyai tanggung jawab untuk menurunkan angka penyakit guna meningkatkan derajat kesehatan masyarakat. Permasalahan yang terjadi di Puskesmas X antara lain: masih ada petugas puskesmas yang kurang memahami kebutuhan dan keinginan pasien $(60,0 \%)$, masih belum ada pemberitahuan dari puskesmas jika dokter yang bertugas terlambat atau berhalangan $(56,7 \%)$, puskesmas belum cepat dalam menangani pasien $(53,3 \%)$ dan obat di puskesmasdirasa tidak lengkap oleh pasien $(53,3 \%)$.

Puskesmas adalah fasilitas pelayanan kesehatan yang menyelenggarakan upaya kesehatan di masyarakat dan upaya kesehatan perseorangan tingkat pertama untuk mencapai derajat kesehatan setinggi tingginya [1].Oleh karena itu sangat penting untuk segera menata fasilitas kesehatan tingkat pertama atau fasilitas kesehatan primer yaitu puskesmas dan hanya yang membutuhkan layanan dokter spesialis atau sub spesialis yang dapat dirujuk ke rumah sakit. Agar masyarakat mau berobat ke fasilitas pelayanan kesehatan primer, maka kualitas layanan kesehatan primer tersebut harus ditingkatkan, baik dari proses maupun peningkatan kompetensi dokter, termasuk cara berkomunikasi dengan pasien [2].

Pemerintah Indonesia menyatakan bahwa pelayanan publik oleh aparatur pemerintah dewasa ini masih banyak dijumpai kelemahan sehingga belum dapat memenuhi kualitas sesuai yang diharapkan oleh masyarakat [3]. Berdasarkan permasalahan di Puskesmas X sebelumnya, permasalahan tersebut 
meliputi sarana kesehatan dan proses pelayanan kesehatan. Sedangkan kualitas pelayanan kesehatan yang diinginkan pemerintah mencakup tiga hal yaitu : sarana dan prasarana, proses pelayanan kesehatan dan manajemen kesehatan [4]. Dari hal-hal tersebut sudah seharusnya Puskesmas X mengetahui bagaimana cara mengukur kualitaspelayanan yang sudah diberikan kepada masyarakat. Pada bidang kesehatan,Servqual[5] merupakan alat yang banyak digunakan untuk mengukur kualitas pelayanan kesehatan [6].Untuk mengukur kualitas pelayanan bidang kesehatan ada lima dimensi Service Qualityyang digunakan yaitu tangible, reliability, responsiveness, assurance dan empathy [5,6].

\section{Metode Penelitian}

\section{Jenis Penelitian}

Jenis penelitian ini menggunakan metode deskriptif dengan pendekatan kuantitatif. Metode deskriptif adalah suatu metode dalam meneliti sekelompok manusia, suatu objek, suatu kondisi, suatu sistem ataupun suatu peristiwa pada masa sekarang [7]. Penelitian ini dikelompokkan dalam metode deskriptif karena penelitian ini bertujuan untuk menggambarkan suatu sistem kegiatan pelayanan yang dilakukan oleh puskesmas. Sedangkan yang dimaksud pendekatan kuantitatif dalam penelitian ini adalah suatu pendekatan yang digunakan untuk memahami objek penelitian dengan menjelaskan keterkaitan antara variabel pada penelitian dengan menggunakan perhitungan statistik [8].

\section{Populasi dan Sampel}

Populasi adalah seluruh pasien yang menggunakan jasa pelayanan di Puskesmas X. Untuk mengetahui jumlah sampel, rata rata jumlah kunjungan pasien Puskesmas $X$ setiap bulannya adalah 2.179 orang. Selanjutnya dengan menggunakan rumus Slovin, pada batas toleransi kesalahan penarikan sampel 10\%didapat jumlah sampel 96 orang. Hasil ini sesuai pendapat Roscoe [9] dalam menentukan acuan umum untuk menentukan ukuran sampel yaitu ukuran sampel lebih dari 30 dan kurang dari 500 adalah tepat untuk kebanyakan penelitian.

\section{Instrumen Penelitian}

Instrumen yang digunakan dalam penelitian ini berbentuk kuesioner dan indikator pada kuesioner tersebut secara teknis dapat diambil dari referensi tertentu yaitu artikel ilmiah, buku atau sumber pendukung lainnya[10]. Instrumen statistik yang digunakan adalah skala Likert $1-5$, dimulai angka 1 yang menunjukkan sangat tidak setuju sampai angka 5 yang menunjukkan sangat setuju.

\section{Metode Pengumpulan Data}

Pengumpulan data dilakukan dengan cara meminta pasien yang sudah mendapat pelayanan puskesmas untuk menjawab semua pertanyaan dari kelima dimensi Servqual, dengan 22 item pertanyaan di dalamnya. Selanjutnya data tersebut akan digunakan sebagai dasar analisis kualitas pelayanan.

\section{Teknik Analisis Data}

\section{Menghitung Mean Gap}

Untuk mengukur kualitas pelayanan pada kelima dimensi Servqual (tangible, reliability, responsiveness, assurance dan empathy) dilakukan dengan menghitung mean gap antara persepsi dan ekspetasi [5]. Untuk melakukan analisis data digunakan software SPSS Version 20 dan manual. Apabila nilai mean gap yang didapatkan negatif maka terjadi kesenjangan antara persepsi dan ekspetasi pasien Puskesmas X.

\section{Analisis Regresi Dimensi Servqual Terhadap Kualitas Pelayanan}

Analisis regresi linier berganda digunakan untuk mengukur pengaruh variable independen terhadap variable dependen [11]. Salah satu tujuan penelitian ini untuk mengetahui variabel Servqualyang paling dominan mempengaruhi kualitas pelayanan Puskesmas X. Untuk melakukan analisis regresi linier berganda digunakan software SPSS Version20, jika nilai signifikan yang didapat kurang dari 0,05 maka data penelitian tersebut signifikan[11]. 


\section{Hasil Penelitian dan Pembahasan}

\section{Uji Validitas dan Reliabilitas Instrumen}

Hasil uji validitas terhadap instrumen penelitian dengan softwareSPSS Version 20 didapatkan nilai $\mathrm{R}$ hitung persepsi dan $\mathrm{R}$ hitung ekspetasi lebih besar dari $\mathrm{R}$ tabel $(0,201)$, sehingga instrumenpada penelitian ini valid. Hasil uji reliabilitasterhadap instrumen penelitian dengan software SPSS Version 20 ditampilkan pada tabel 1. Hasilnya semua nilai Cronbach's Alpha dimensi Servqual persepsi maupun ekspektasi lebih besar dari 0,6 maka instrumen yang digunakan reliabel.

Tabel 1 Hasil Uji Reliabilitas Instrumen Persepsi dan Ekspetasi

\begin{tabular}{|l|c|c|c|c|c|c|}
\hline \multirow{2}{*}{$\begin{array}{c}\text { Dimensi } \\
\text { Servqual }\end{array}$} & $\begin{array}{c}|c| \\
\text { Cronbach's } \\
\text { Alpha }\end{array}$ & $\begin{array}{c}\text { Nof } \\
\text { Items }\end{array}$ & Keterangan & $\begin{array}{c}\text { Cronbach's } \\
\text { Alpha }\end{array}$ & $\begin{array}{c}\text { Nof } \\
\text { Items }\end{array}$ & Keterangan \\
\hline Tangible & 0,773 & 4 & Reliabel & 0,880 & 4 & Reliabel \\
\hline Reliability & 0,721 & 5 & Reliabel & 0,862 & 5 & Reliabel \\
\hline Responsiveness & 0,778 & 4 & Reliabel & 0,854 & 4 & Reliabel \\
\hline Assurance & 0,725 & 4 & Reliabel & 0,801 & 4 & Reliabel \\
\hline Empathy & 0,668 & 5 & Reliabel & 0,814 & 5 & Reliabel \\
\hline \multicolumn{7}{|r|}{ Jumlah item } \\
\hline
\end{tabular}

\section{Mean Gap Persepsi dan Ekspetasi Pasien}

Pada penelitian ini digunakan analisis meangap untuk mengetahui kesenjangan antara persepsidanekspetasipasienpada kelimadimensiServqual. Penelitian sebelumnya $[12,13]$ yang menggunakan analisis mean gap dijelaskan sebagai berikut, penelitian delapan puskesmas di Kota Palembang [12] menggunakan 20 item Servqual. Penelitian dilakukan dengan cara mengukur dan membandingkan mean persepsi pasien pada kelima dimensi Servqual, kemudian mendeskripsikannya. Berikutnya mengukur meangap persepsi dan ekspetasi pasien, kemudian melakukan analisis tiga gap terbesar pada masing masing puskesmas. Hasil penelitian menunjukan bahwa kualitas pelayanan kesehatan masyarakat di Kota Palembang menurut persepsi pasien lebih rendah dari yang diharapkan pasien.

Penelitian berikutnya [13] menghitung nilai meangap antara persepsi dengan ekspetasi menggunakan 22item Servqualpada PuskesmasBerastagi Kabupaten Karo, kemudian dilakukan analisis pada gap terbesar dan gapterkecil pada setiap dimensiServqual.Hasil penelitian menunjukan masih ada gap pada pelayanan Puskesmas Berastagi Kabupaten Karo.

Berdasarkan kedua penelitian tersebut, maka pada penelitian ini akan dilakukan analisis pada nilai meangapsemua dimensiServqualyang digunakan. Hasilnya ditampilkan pada tabel 2 berikut ini. Pada tabel 2 terlihat bahwa semua nilai mean gap pada dimensiServqual bernilai negatif, dapat disimpulkan nilai ekspetasi pasien puskesmas lebih tinggi dari persepsinya sehingga terjadi kesenjangan antara persepsi dan ekspetasi pasien terhadap kualitas pelayanan Puskesmas X. 
Tabel 2. Mean Gap Dimensi Servqual

\begin{tabular}{|c|c|c|}
\hline Item & Dimensi Servqual & MeanGap \\
\hline & Tangible & \\
\hline$(1.3)$ & Karyawan puskemas berpenampilan rapi. & $-0,3438$ \\
\hline$(1.1)$ & Puskesmas memiliki peralatan yang modern dan terbaru. & $-0,3958$ \\
\hline$(1.2)$ & Fasilitas puskesmas tampak menarik. & $-0,4063$ \\
\hline \multirow[t]{2}{*}{$(1.4)$} & Obat di puskesmas lengkap. & $-0,5625$ \\
\hline & Reliability & \\
\hline$(2.3)$ & Puskesmas melakukan pelayanan yang baik sejak awal. & $-0,3750$ \\
\hline$(2.1)$ & Puskesmas selalu menepati apa yang sudah dikatakan. & $-0,4479$ \\
\hline$(2.5)$ & Puskesmas mempunyai catatan yang lengkap. & $-0,4583$ \\
\hline Item & Dimensi Servqual & MeanGap \\
\hline$(2.2)$ & Puskesmas mampu memecahkan masalah pasien. & $-0,4792$ \\
\hline \multirow[t]{2}{*}{$(2.4)$} & Puskesmas menyediakan layanan sesuai yang mereka janjikan. & $-0,4896$ \\
\hline & Responsiveness & \\
\hline$(3.2)$ & Puskesmas memberikan pelayanan secara cepat dan tepat. & $-0,2708$ \\
\hline$(3.1)$ & $\begin{array}{l}\text { Puskesmas memberitahukan kepada pasien kapan pelayanan } \\
\text { diberikan. }\end{array}$ & $-0,2813$ \\
\hline$(3.4)$ & Puskesmas selalu siap menanggapi permintaan pasien. & $-0,3438$ \\
\hline \multirow[t]{2}{*}{$(3.3)$} & Puskesmas selalu siap membantu pasien. & $-0,4583$ \\
\hline & Assurance & \\
\hline$(4.1)$ & Pasien dapat mempercayai kemampuan pegawai puskesmas. & $-0,2813$ \\
\hline$(4.2)$ & Pasien merasa aman ketika dilayani pegawai puskesmas. & $-0,3229$ \\
\hline$(4.3)$ & Pegawai puskesmas tetap sopan terhadap pasien. & $-0,4375$ \\
\hline \multirow[t]{2}{*}{$(4.4)$} & $\begin{array}{l}\text { Pegawai puskesmas mempunyai pengetahuan menjawab } \\
\text { pertanyaan pasien. }\end{array}$ & $-0,5104$ \\
\hline & Empathy & \\
\hline$(5.4)$ & $\begin{array}{l}\text { Puskesmas menempatkan kepentingan pasien sebagai prioritas } \\
\text { utama. }\end{array}$ & $-0,3021$ \\
\hline$(5.2)$ & $\begin{array}{l}\text { Puskesmas memiliki jam kerja yang nyaman untuk semua } \\
\text { pasien. }\end{array}$ & $-0,3125$ \\
\hline$(5.1)$ & Manajemen puskesmas memberikan perhatian kepada pasien. & $-0,3333$ \\
\hline$(5.3)$ & Pegawai puskesmas memberikan perhatian kepada pasien. & $-0,3438$ \\
\hline$(5.5)$ & Pegawai puskesmas mengerti kebutuhan khusus pasien. & $-0,3646$ \\
\hline
\end{tabular}

\section{Saran Perbaikan}

Saran perbaikan ini ditampilkan pada tabel 3 dan dapat digunakan oleh manajemen Puskesmas $\mathrm{X}$ untuk melakukan upaya perbaikan dan meningkatkan kualitas pelayanan Puskesmas X. 
Tabel 3. Saran Perbaikan Dimensi Servqual

\begin{tabular}{|c|c|}
\hline Item & Saran Perbaikan \\
\hline & Tangible \\
\hline (1.3) & Membuat peraturan bagi pegawainya tentang pakaian seragam dan kelengkapannya. \\
\hline$(1.1)$ & Melakukan pembaharuan dan pengorganisasian kelengkapan fasilitas pelayanan. \\
\hline$(1.2)$ & Melengkapi fasilitas yang ada seperti pengeras suara serta memperbaiki area parkir. \\
\hline \multirow[t]{2}{*}{$(1.4)$} & Menyediakan brosur dan poster berisi informasi kelengkapan dan kegunaan obat generik. \\
\hline & Reliability \\
\hline$(2.3)$ & Mempercepat pembukaan loket pendaftaran, misalkan 15 sampai 30 menit lebih cepat. \\
\hline (2.1) & Membuat sistem absen yang lebih transparan, dengan pengadaan jam absen elektronik. \\
\hline$(2.5)$ & Meningkatkan penggunaan sistem infomasi manajemen puskesmas (simpus). \\
\hline$(2.2)$ & Meningkatkan kompetensi pegawai puskesmas melalui pelatihan. \\
\hline \multirow[t]{2}{*}{$(2.4)$} & Penambahan tenaga dokter khususnya dokter spesialis. \\
\hline & Responsiveness \\
\hline$(3.2)$ & $\begin{array}{l}\text { Tanggap terhadap keluhan pasien, pasien dapat menyampaikan secara lisan dan dapat } \\
\text { bertanya langsung kepada petugas puskesmas atau melalui kotak saran. }\end{array}$ \\
\hline$(3.1)$ & $\begin{array}{l}\text { Membuat papan informasi yang menunjukkan waktu mulai dan waktu standar lama suatu } \\
\text { pelayanan. }\end{array}$ \\
\hline$(3.4)$ & $\begin{array}{l}\text { Mempersiapkan diri dengan baik dalam memenuhi permintaan pasien, mengenai ruang } \\
\text { periksa, puskesmas membuat ruang periksa permanen dan tidak hanya ditutup kelambu. }\end{array}$ \\
\hline \multirow[t]{2}{*}{$(3.3)$} & $\begin{array}{l}\text { Mendidik petugas tentang strategi penanganan keluhan yang efektif dan penggunaan } \\
\text { komunikasi yang sesuai dengan karakteristik pasien. }\end{array}$ \\
\hline & Assurance \\
\hline (4.1) & $\begin{array}{l}\text { Meningkatkan kepercayaan masyarakat kepada kemampuan pegawai puskesmas dengan } \\
\text { menampilkan sertifikat atau pengalaman kerja dari dokter puskesmas. }\end{array}$ \\
\hline Item & Saran Perbaikan \\
\hline (4.2) & $\begin{array}{l}\text { Untuk meningkatkan rasa aman para pegawai puskesmas wajib menjelaskan dan } \\
\text { memberikan kelengkapan informasi tentang tindakan yang akan dilakukan pada pasien. }\end{array}$ \\
\hline (4.3) & $\begin{array}{l}\text { Pegawai puskesmas tetap dapat bersikap sopan dengan cara setiap hasil pemeriksaan } \\
\text { dikomunikasikan kepada pasien secara jelas disesuaikan dengan daya tangkap pasien. }\end{array}$ \\
\hline \multirow[t]{2}{*}{$(4.4)$} & $\begin{array}{l}\text { Melakukan peningkatan pengetahuan dan keterampilan yang dibutuhkan oleh seluruh } \\
\text { petugas sesuai dengan keahlian masing masing, terutama bagi petugas yang berhadapan } \\
\text { langsung dengan pasien. }\end{array}$ \\
\hline & Empathy \\
\hline$(5.4)$ & $\begin{array}{l}\text { Petugas yang bertugas di ruang periksa atau pengobatan dokter dan dokter gigi dapat } \\
\text { menyambut pasien yang datang dari pintu masuk ruangan dan mengantarkannya } \\
\text { kembali.Petugas juga diwajibkan mengingat nama pasien dan keluhan penyakitnya ketika } \\
\text { sedang melakukan konsultasi untuk meningkatkan keeratan dan kehangatan komunikasi. }\end{array}$ \\
\hline$(5.2)$ & $\begin{array}{l}\text { Puskesmas X sebaiknya menambah jam buka puskesmas sampai jam } 15.00 \text { sesuai harapan } \\
\text { para pasien. Jika puskesmas buka lebih lama maka masyarakat yang dilayani memiliki } \\
\text { waktu yang leluasa dalam mendapatkan pelayanan. }\end{array}$ \\
\hline$(5.1)$ & $\begin{array}{l}\text { Manajemen puskesmas sebaiknya menambah jumlah tindakan medis yang dikenakan } \\
\text { pembebasan biaya dalam pelayanan pasien. }\end{array}$ \\
\hline$(5.3)$ & $\begin{array}{l}\text { Karena Puskesmas X berada di wilayah yang didominasi suku Jawa, maka diperlukan } \\
\text { adanya pelatihan penggunaan bahasa Jawa yang halus, sopan dan mengerti unggah ungguh } \\
\text { atau tata krama dan puskesmas dapat memasukkan keramahan sebagai salah satu kriteria } \\
\text { penilaian kinerja petugas puskesmas. }\end{array}$ \\
\hline$(5.5)$ & $\begin{array}{l}\text { Perhatian kepada kebutuhan khusus pasien dapat dilakukan dengan cara saat seorang } \\
\text { pasien mengeluh tentang penyakit yang dideritanya maka petugas puskesmas harus } \\
\text { mengetahui penyakit apa saja yang diderita pasien tersebut untuk selanjutnya mendapatkan } \\
\text { pemeriksaan dan pengobatan sesuai penyakit yang dikeluhkan tersebut. }\end{array}$ \\
\hline
\end{tabular}




\section{Pengaruh Dimensi Servqual Terhadap Kualitas Pelayanan}

Hasil analisis regresi linier bergandaditampilkan pada tabel 4 dandidapatkan semua dimensi Servqualberpengaruh terhadap kualitas pelayanan Puskesmas X. Dimensi Servqualyang paling berpengaruh terhadap kualitas pelayanan puskesmas adalah dimensi assurance dengan nilai signifikan 0,000 dan memiliki hubungan positif sebesar 1,367. Dari hasil ini dapat disimpulkan bahwa apabila kualitas pelayanan dimensi assurance ditingkatkan maka kualitas pelayanan Puskesmas X akan lebih meningkat. Semua nilai signifikan kurang dari 0,05 maka semua dimensi Servqualmempunyai pengaruh signifikan terhadap kualitas pelayanan Puskesmas X.

Tabel 4. Hasil Regresi Dimensi Servqual

\begin{tabular}{|c|c|c|c|c|}
\hline No & Dimensi Servqual & Koefisien Regresi & Sig & Keterangan \\
\hline 1 & Assurance & 1,367 & 0,000 & Berpengaruh \\
\hline 2 & Responsiveness & 1,361 & 0,000 & Berpengaruh \\
\hline 3 & Tangible & 0,943 & 0,001 & Berpengaruh \\
\hline 4 & Empathy & 0,801 & 0,002 & Berpengaruh \\
\hline 5 & Reliability & 0,747 & 0,014 & Berpengaruh \\
\hline
\end{tabular}

\section{Kesimpulan}

Berdasarkan hasil perhitungan mean gap antara persepsi dan ekspetasi didapatkan nilai ekspetasi pasien Puskesmas X lebih tinggi dari persepsinya sehingga terjadi kesenjangan atau gap pada pelayanan puskesmas. Saran perbaikan yang diberikan dapat digunakan oleh manajemen puskesmas untuk melakukan upaya perbaikan pelayanan di Puskesmas X.

Hasil analisis regresi menunjukkan dimensi Servqualyang paling berpengaruh terhadap kualitas pelayanan di Puskesmas X adalah assurance. Untuk meningkatkan kualitas pelayanan pada Puskesmas $\mathrm{X}$ khususnya pada dimensi assurancedapat dilakukan dengan: meningkatkan kepercayaan masyarakat kepada kemampuan pegawai puskesmas dengan menampilkan sertifikat atau pengalaman kerja dokter puskesmas di tempat yang mudah dilihat pasien, untuk meningkatkan rasa aman maka pegawai puskesmas wajib menjelaskan dan memberikan kelengkapan informasi tentang tindakan yang akan dilakukan kepada pasien, pegawai puskesmas tetap dapat bersikap sopan dengan cara setiap hasil pemeriksaan dikomunikasikan kepada pasien secara jelas disesuaikan dengan daya tangkap pasien dan puskesmas harus meningkatkan pengetahuan dan keterampilan yang dibutuhkanseluruh petugas puskesmas disesuaikan dengan keahlian masing masing terutama bagi petugas yang berhadapan langsung dengan pasien.

\section{Daftar Referensi}

[1] Peraturan Menteri Kesehatan Republik Indonesia Nomor 75 Tahun 2014 tentang Puskesmas.

[2] Meliala, A.(2012).Peneliti Pusat Manajemen Pelayanan Kesehatan Fakultas Kedokteran Universitas Gadjah Mada. [Online]. Available: http:// www.Kompas.com.

[3] Keputusan Menteri Pendayagunaan Aparatur Negara Nomor 25 tahun 2004 tentang Pelayanan Publik.

[4] Undang Undang Republik Indonesia Nomor 44 tahun 2009 tentang Rumah Sakit.

[5] Parasuraman, A., Zeithaml, V., and Berry, L. (1990).A conceptual model of service quality and its implications for future research. Journal of Marketing, vol. 49, pp. 41-50.

[6] Chakraborty and Majumdar. (2011). Measuring Consumer Satisfaction In Health Care Sector: The Applicability Of Servqual. Journal of Arts, Science \& Commerce, vol. 2, pp. 149 - 152.

[7] Umar, H. (2002). Riset pemasaran dan perilaku konsumen. Jakarta : Gramedia Pustaka Utama.

[8] Supardi. (2013). Aplikasi Statistik Dalam Penelitian. Jakarta: Change Publication.

[9] Sekaran, Uma. (2011). Metodologi Penelitian Untuk Bisnis. Jakarta: Salemba Empat.

[10] Santoso, Singgih. (2015). Menguasai Statistik Multivariat. Jakarta: Elex Media Komputindo.

[11] Santoso, Singgih. (2016). Panduan Lengkap SPSS Versi 23. Jakarta: Elex Media Komputindo.

[12] Saptawan, Ardiyan dan Nengyanti. (2014). Efektivitas Kualitas Pelayanan Kesehatan Masyarakat. Jurnal Ilmu Administrasi Negara, vol12,no 4, hlm 241- 256. 
Jurnal Teknologi dan Manajemen Industri, Vol. 3 No. 1, Februari 2017

Pascasarjana Institut Teknologi Nasional Malang

[13] Ginting, Tamaseri.(2012). Analisis Kualitas Pelayanan Rawat Jalan Puskesmas Berastagi Kabupaten Karo.Tesis.Program Magister Perencanaan dan Kebijakan Publik. Universitas Indonesia. Jakarta. 